\title{
Allelopathic activities of selected Mucuna pruriens on the germination and initial growth of lettuce
}

\author{
Kwame Sarpong APPIAH ${ }^{1,2}$, Christiana Adukwei AMOATEY ${ }^{2}$, Yoshiharu FUJII ${ }^{1}$ * \\ ${ }^{1}$ Department of International Environmental and Agricultural Science, Tokyo University of Agriculture and Technology, 3-5-8, \\ Saiwai-Cho, Fuchu Tokyo 183-8509, Japan \\ ${ }^{2}$ Department of Crop Science, University of Ghana, P. O. Box LG 44. Legon-Accra, Ghana \\ *Corresponding author E-mail: yfujii@cc.tuat.ac.jp
}

Copyright $\odot 2015$ Kwame Sarpong Appiah et al. This is an open access article distributed under the Creative Commons Attribution License, which permits unrestricted use, distribution, and reproduction in any medium, provided the original work is properly cited.

\begin{abstract}
The study was conducted to test allelopathic effects of some Mucuna pruriens on the germination and growth of lettuce. The effects of root exudates and leaf leachates of eight mucuna genotypes; Mucuna pruriens var. utilis cv. cinza, Mucuna pruriens var. utilis cv. preta, Mucuna pruriens var. utilis cv. hassjo, Mucuna pruriens var. utilis cv. fvb, Mucuna pruriens 82/507, Mucuna pruriens 82/508, Mucuna pruriens 82/116, and Mucuna pruriens GA/94/002 were tested on the germination, radicle, and hypocotyl elongations of lettuce (Lactuca sativa var. Great Lakes 366). The effects of leaf leachates and root exudates of mucuna were tested using sandwich and plant-box methods respectively with lettuce as the receptor plant. Roots exudates inhibition varied significantly among genotypes (94.3\%-98.5\%). Root exudates of Mucuna pruriens var. utilis cv. fvb had the maximum inhibition (98.5\%). Lettuce radicle inhibition gradually decreased with distance from the mucuna plant in a plant-box and with high correlation $(\mathrm{r}=0.910-0.952$; $\mathrm{p}<0.05)$ between lettuce radicle inhibition and distance from mucuna roots. The effect of $50 \mathrm{mg}$ oven-dried mucuna leaves had significant inhibition on lettuce radicle elongation (12.0\%-15.8\% of untreated control). Leaf leachates had less effect on the hypocotyl elongation of lettuce (50.5\%-72.0\% of untreated control) at the same application of ovendried leaves $(50 \mathrm{mg} / 10 \mathrm{ml}$ agar).
\end{abstract}

Keywords: Allelopathy; Elongation; Exudates; Leachates; Inhibition.

\section{Introduction}

The control of weeds on the field is a major impediment to crop production in most developing Sub-Saharan African countries including Ghana. As a result, weeds have influenced human social actions more than other crop pests yet they are mostly underestimated in tropical agriculture [1]. In modern agricultural practices, herbicides are widely used to control weeds but there are some environmental concerns about their excessive use and also cases of herbicide resistant/tolerant weeds are gradually on the rise [2]. Mucuna pruriens is among the most promising legumes currently being promoted as cover crop and green manure in tropical agriculture especially among the Sub-Saharan African countries. Farmers in the forest and transition zones of Ghana for over a century have been planting few stands of this legume for food [3]. Mucuna exhibited significant weed suppression abilities in the range of $79-90 \%$ and fixed an amount of soil nitrogen in the range of $333-495 \mathrm{mg} \mathrm{N} / \mathrm{plant}$ under field conditions [4]. Imperata cylindrica is a strong competitor to field crops especially maize in West Africa causing up to about 50\% yield loss in maize production although the field had been weeded twice [5]. Over a three-year period, mucuna reduced the dry matter content of Imperata cylindrica by 58-89\% [6]. Osei et al. [7] reported yield improvement of pineapple from weed free-mucuna plots recording 51 tons/ha, while bush fallow treatment recorded 34 tons/ha. The time interval between incorporation of mucuna and planting of maize had effect on growth and yield of maize. Grain yields of maize were 1.39 and $0.80 \mathrm{t} / \mathrm{ha}$ respectively for four weeks and one week intervals of mucuna incorporation [8]. Mucuna has also been reported to be effective in the control of some plant parasitic nematodes. In developing countries of the tropical and sub-tropical 
climates, crop production losses due to nematodes have been estimated at $14.6 \%$ compared with $8.80 \%$ in developed countries [9]. Undiluted crude extracts from mucuna decreased the survival of Meloidogyne incognita J2 in the range of $29-56 \%$ [10]. Root-knot nematodes failed to multiply on mucuna even though they significantly reduced growth of Crotalaria ochroleuca by $36 \%$ and thus mucuna is not a host to Meloidogyne arenaria race 2, M. incognita race 1, M. javanica, Pratylenchus zeae, and Heterodera glycine [11], [12], [13]. The term allelopathy describes beneficial and mostly harmful natural interactions between organisms due to the production and release of natural bioactive chemicals (secondary metabolites) from the donor organism to the receptor organism. The secondary metabolites related to this phenomenon are called allelochemicals and are mostly released into the environment by ecological processes of volatilization, leaching, root exudation, and/or by the decomposition of plant residues [14]. Some invasive plant species are successful because they possess novel biochemical compounds that function as allelopathic agent or as mediators of the new plant-plant interactions [15]. Plants that are able to suppress and/or eliminate competing plant species near the source plant have currently received much attention and there is the growing possibilities of compounds from most of these plant being used as selective natural herbicides [16], [17]. The crude extract of fresh leaves and stems of hairy vetch (Vicia villosa) showed inhibitory activity on hypocotyl and radicle elongation of lettuce to a level of 50\% [18]. Continuous cropping of mucuna on the field reduced weeds to about half of the fallow plots and one quarter of the plots with other crops such as upland rice, eggplant, and tomato [19]. Fujii et al., [20] reported L-3, 4Dihydroxyphenylalanine (L-DOPA) as the allelochemical in mucuna inhibiting plant growth.

Allelopathic plants and their allelochemicals are therefore important potential source for alternate weed management in order to solve the many problems arising from inadequate cultural practices and the indiscriminate use of synthetic herbicides. Not all mucuna genotypes have however been screened for allelopathic activities hence the objective of this study was to evaluate the allelopathic activities of some selected mucuna genotypes on the germination and growth (radicle and hypocotyl elongation) of lettuce.

\section{Materials and methods}

\subsection{Donor plant}

For the purpose of this study, the allelopathic activities of the selected mucuna genotypes were assayed on agar by the plant-box method [21] for root exudates and the sandwich method [22] for leaf leachates. Seeds of eight (8) mucuna genotypes used in the study were obtained from the Laboratory of International Agro-Biological Resources and Allelopathy (Tokyo University of Agriculture and Technology, Japan) and Plant Genetic Resources Centre (Bunso, Ghana). The seeds were grown under greenhouse conditions in 2013 at Tokyo University of Agriculture and Technology for two months before use in the bioassay experiments. The eight (8) genotypes used in this study are Mucuna pruriens var. utilis cv. cinza, Mucuna pruriens var. utilis cv. preta, (Brazil) Mucuna pruriens var. utilis cv. hassjo, (Japan) Mucuna pruriens var. utilis cv. fvb (common name: Florida velvet bean, U.S.A), Mucuna pruriens 82/507, Mucuna pruriens 82/508, Mucuna pruriens 82/116, and Mucuna pruriens GA/94/002 (Ghana).

\subsection{Receptor plant}

Lettuce (Lactuca sativa var. Great Lakes 366) was used as the receptor plant for all the bioassay experiments. Lettuce was selected because of its universal usage and high sensitivity to bioactive substances. It also has rapid germination. High quality viable lettuce seeds were used.

\subsection{Preparation of growing medium for sandwich and plant-box bioassay laboratory experiment}

The most appropriate gel-support for the plant-box and the sandwich methods was selected based on recommendation [22]. Agar powder (gelling temperature $30-31^{\circ} \mathrm{C}$, Nacalai Tesque, Kyoto, Japan) was selected as growth medium in this study. An agar solution was prepared as $0.75 \%(w / v)$ of Nacalai Tesque agar powder and autoclaved using Tomy LSX500 with High Pressure Stream Sterilizer for 20 minutes at $120^{\circ} \mathrm{C}$. The agar solution was left to cool to $40^{\circ} \mathrm{C}$ in water bath prior to its use.

\subsection{Sandwich method to test allelopathic activity of leaf leachates from mucuna on lettuce germinating seeds}

The sandwich method [22] was adopted to assay the activities of leachates from donor plant leaves. At the fourth leaf stage of the mucuna seedlings, the leaves of each plant species were collected fresh and placed separately in paper bag. The leaves were oven-dried at $60^{\circ} \mathrm{C}$ for 24 hours. The oven-dried leaves were kept in a plastic bag in an airtight box until further use. Multi-well plastic plates with six wells $\left(10 \mathrm{~cm}^{2}\right.$ per each well) were separately filled with $10 \mathrm{mg}$ and $50 \mathrm{mg}$ oven-dried leaves of each mucuna genotype (3 wells each). Using a microliter pipette, $5 \mathrm{~mL}$ of the autoclaved 
agar was added to each of the 6 wells of multi-well plastic plate (36 mm×18 mm, Nalge Nunc Int.). After gelatinizing the agar for 30 minutes at room temperature, another $5 \mathrm{~mL}$ of the autoclaved agar was added to each well of the multiwell plastic plates. The agar was again allowed to gelatinize for 30 minutes at room temperature. This set-up allowed oven-dried leaves to be sandwiched between the two layers of the agar hence the name. After gelatinizing the agar, five lettuce seeds were placed in each well of the multi-well plastic plate using ceramic tweezers. The untreated control contained only agar substrate. After seeding, the multi-well plastic plates were sealed with plastic tape and labeled appropriately. The set-up was kept in an incubator (NTS Model MI-25S) in complete randomized design for 3 days at $25^{\circ} \mathrm{C}$ in complete darkness. The germination percentage of the seeds was recorded and the radicle and hypocotyl lengths of the lettuce seedlings were also measured after the 72 hours of incubation. Three replicates were set for each treatment and the means of these represent the results.

\subsection{Plant-box bioassay method to test allelopathic effect of root exudates of mucuna on lettuce}

Allelopathic activities of live plant exudates from the eight mucuna plant samples indicated above were assayed using the plant-box method developed by Fujii et al., [21]. Mucuna seedlings grown in the greenhouse were uprooted after two months. All soil particles were washed from the root and the seedlings were transplanted into a root-zone separating tubes (nylon tube, $32 \times 25 \times 65 \mathrm{~mm}$ ) attached to one corner of the plant-box (Magenta GA-7 of dimensions $65 \times 65 \times 100$ $\mathrm{mm})$. Plant-box without mucuna plants was prepared as the untreated control. Autoclaved agar was cooled to $40^{\circ} \mathrm{C}$ and added to the plant-box until the $65 \mathrm{~mm}$ height mark on the plant-box was reached. The plant-boxes with the agar were kept in water bath for one hour to gelatinize. Thirty-three lettuce seeds were sown on the agar gel substrate in each plant-box after the agar had gelatinized. The plant-boxes were arranged in a complete randomized design in a growth chamber (Biotron NK System) at $25 / 20^{\circ} \mathrm{C}$ with 12 hours of daytime for five days. Three replicates were set for each mucuna genotype and the control. The daily conditions of the samples were checked and $5 \mathrm{~mL}$ of distilled water was added to the plant boxes from day 2 to day 4 . The percentage germination of lettuce seeds was recorded and the radicle and hypocotyl lengths of lettuce seedlings were also recorded after five days in the growth chamber. Allelopathic activity of each of the plant samples was evaluated from the intercept value from the linear regression curve which was obtained from the relationship between the distance of lettuce seedlings away from root-zone separating tube and the lettuce radicle length.

\subsection{Statistical analysis}

Statistical analysis was performed using GenStat version 9 software program. The data were subjected to analysis of variance (ANOVA) to determine the effects of mucuna treatment on lettuce germination, radicle and hypocotyl elongations. Mean differences among treatments were compared using least significance difference (LSD) test at; $\mathrm{p}<0.05$.

\footnotetext{
Elongation $\%=\underline{\text { (Average length of treatment radicle/hypocotyl })} \times 100$

(Average length of control radicle/hypocotyl)
}

\section{Results and discussions}

\subsection{Allelopathic effects of mucuna leaf leachates on lettuce growth}

Allelopathic activities of eight mucuna genotypes on the radicle and hypocotyl elongation of lettuce were tested using the sandwich method. Table 1 presents percentages of lettuce radicle and hypocotyl elongation using the sandwich method. Radicle elongations of lettuce were $37.2-50.8 \%$ and $12-15 \%$ of the untreated control when treated with 10 and $50 \mathrm{mg}$ of the oven-dried mucuna leaves respectively (Table 1). The leachates from mucuna leaves inhibited radicle elongation of lettuce more than the hypocotyl. Lettuce hypocotyl elongation was stimulated to $104 \%$ and $103 \%$ for Mucuna pruriens GA/94/002 and Mucuna pruriens var. utilis cv. preta respectively when $10 \mathrm{mg}$ oven-dried leaves were used. Shiraishi et al., [23] reported lettuce hypocotyl stimulation by Oxalis tuberosa, Artemisia capillaris, and Coreopsis tinctoria to $130 \%, 120 \%$, and $110 \%$ respectively for $10 \mathrm{mg}$ oven-dried mucuna leaves treatment. Allelopathic effects by the leaf leachates among all the genotypes varied significantly from the control with Mucuna pruriens GA/94/002 having the most significant inhibition on lettuce radicle (12\% of the untreated control).

\subsection{Effects of mucuna root exudates on growth of lettuce}

Mucuna root exudates inhibited lettuce radicle growth in the plant box bioassay (Table 2). Lettuce radicle inhibitions ranged from 94.0\%-98.5\%. Nishihara et al., [24] reported more than 90.0\% growth inhibition with Mucuna pruriens var. utilis cv. jaspeada having the maximum inhibition (96\%). In this study, Mucuna pruriens var. utilis cv. fvb had the most lettuce radicle inhibition with an average of $98.5 \%$. The root exudates of other mucuna cultivar as Mucuna pruriens var. 
utilis cv. ana was reported with $89 \%$ inhibition on the radicle length of lettuce [14]. There was a significant correlation $(\mathrm{r}=0.942 ; \mathrm{p}<0.05)$ between the radicle length of lettuce and the distance from the roots of mucuna (Mucuna pruriens var. utilis cv. $f v b$ ). Nishihara et al., [24] reported high correlation co-efficient $(\mathrm{r}=0.838$ to 0.982$)$ based on diffusion of LDOPA concentration and distances from mucuna roots in the plant-box. In this study, more inhibitory activities were observed near the roots of the mucuna plants, thus when distances between the lettuce seedling and the roots of mucuna were less than $25 \mathrm{~mm}$ (Fig. 1). This observation agrees with the findings of Nishihara et al., [24] who reported that the concentration of diffused L-DOPA decreased exponentially with distance from the roots of mucuna. These results suggested that the exudates from mucuna roots might only have effect on plants that are very close.

Table 1: Lettuce Radicle and Hypocotyl Elongation (Percentage of Untreated Control) as Affected by 8 Mucuna Genotypes Under Different Application Using the Sandwich Method.

\begin{tabular}{|c|c|c|c|c|}
\hline \multirow{4}{*}{ Mucuna genotypes } & \multicolumn{4}{|c|}{ Oven-dried leaf content (per $10 \mathrm{ml}$ agar) } \\
\hline & \multicolumn{2}{|c|}{ Radicle } & \multicolumn{2}{|c|}{ Hypocotyl } \\
\hline & $10 \mathrm{mg}$ & $50 \mathrm{mg}$ & $10 \mathrm{mg}$ & $50 \mathrm{mg}$ \\
\hline & \multicolumn{4}{|c|}{ Percentage of untreated control (100\%) } \\
\hline Mucuna pruriens var. utilis cv. fvb (U.S.A) & 48.2 & 15.0 & 86.5 & 55.5 \\
\hline Mucuna pruriens var. utilis cv. hassjo (Japan) & 37.2 & 13.8 & 79.5 & 53.0 \\
\hline Mucuna pruriens var. utilis cv preta (Brazil) & 50.8 & 14.8 & 104 & 62.5 \\
\hline Mucuna pruriens var. utilis cv. cinza (Brazil) & 44.5 & 13.8 & 89.0 & 50.5 \\
\hline Mucuna pruriens GA/94/002 (Ghana) & 43.8 & 12.0 & 103 & 59.5 \\
\hline Mucuna pruriens 82/507 (Ghana) & 46.5 & 14.5 & 99.5 & 64.2 \\
\hline Mucuna pruriens 82/116 (Ghana) & 48.2 & 13.5 & 87.8 & 59.0 \\
\hline Mucuna pruriens 82/508 (Ghana) & 44.5 & 15.8 & 99.2 & 72.0 \\
\hline
\end{tabular}

Values are expressed as a percentage of each length of the untreated control. Values approaching 100\% indicates no inhibitory activity.

Table 2: The Inhibition of Lettuce Radicle Growth by Different Mucuna Genotypes Using the Plant-Box Bioassay.

\begin{tabular}{|c|c|c|}
\hline Mucuna genotypes & $\begin{array}{c}* \text { Radicle inhibition } \\
(\% \text { of the untreated control) }\end{array}$ & $\mathrm{r} \dagger$ \\
\hline Mucuna pruriens var. utilis cv. fvb (U.S.A) & $98.5 \mathrm{a}$ & 0.942 \\
\hline Mucuna pruriens var. utilis cv. hassjo (Japan) & $97.7 \mathrm{a}$ & 0.934 \\
\hline Mucuna pruriens var. utilis cv preta (Brazil) & $97.4 \mathrm{a}$ & 0.923 \\
\hline Mucuna pruriens var. utilis cv. cinza (Brazil) & $96.7 \mathrm{a}$ & 0.915 \\
\hline Mucuna pruriens GA/94/002 (Ghana) & $95.0 \mathrm{a}$ & 0.952 \\
\hline Mucuna pruriens 82/507 (Ghana) & $97.0 \mathrm{a}$ & 0.910 \\
\hline Mucuna pruriens 82/116 (Ghana) & $96.2 \mathrm{a}$ & 0.920 \\
\hline Mucuna pruriens 82/508 (Ghana) & $94.3 \mathrm{~b}$ & 0.912 \\
\hline
\end{tabular}

\subsection{Effects of mucuna root exudates and leaf leachates on the germination of lettuce}

Of all the mucuna genotypes evaluated, root exudates and leaf leachates did not have negative effects on the germination percentage of lettuce seeds. These observations correspond to work by Fujii et al. [19] which reported that mucuna had no effect on seed germination when lettuce seeds were treated with mucuna leaves, stem, and root extracts. However, morphological observation of lettuce radicle in the plant-box showed that lettuce seedlings in and around the root-zone separating tube had some discoloration. Some of the lettuce radicles in the root-zone separating tube were very thin and fragile and could be detached easily compared to that of the control. Radicle tip of lettuce in the sandwich method also had some discoloration but this was less than that from the plant-box method. The observable features of the lettuce radicle agree with some characteristic effects of allelochemicals such as reduced radicle and hypocotyl elongation, darkened and fragile roots and seeds described by Bhadoria [25]. Under field conditions, Eucharia and Edward, [26] reported that mucuna had no significant inhibition on the germination of Sphenostylis stenocarpa but became marked with seedling emergence and growth. Shiraishi et al. [23] also reported dark and grey coloration of lettuce seeds when treated with L-DOPA. Some plant seeds have the ability to dissolve the allelochemical in mucuna (L-3, 4-Dihydroxyphenylalanine) and therefore show no signs of discoloration. Similar observations were made by Mushtaq et al., [27] and they suggested that the dark coloration of lettuce radicle was due to the formation of melanin from the metabolism of L-DOPA which produced reactive quinones. 


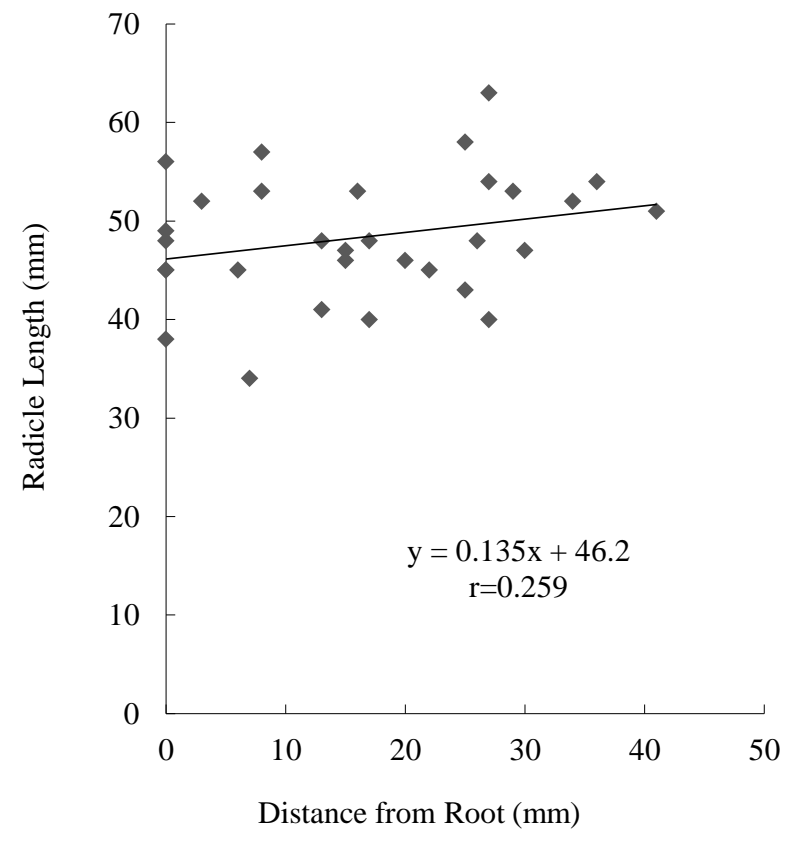

- Radicle L Linear (Radicle)

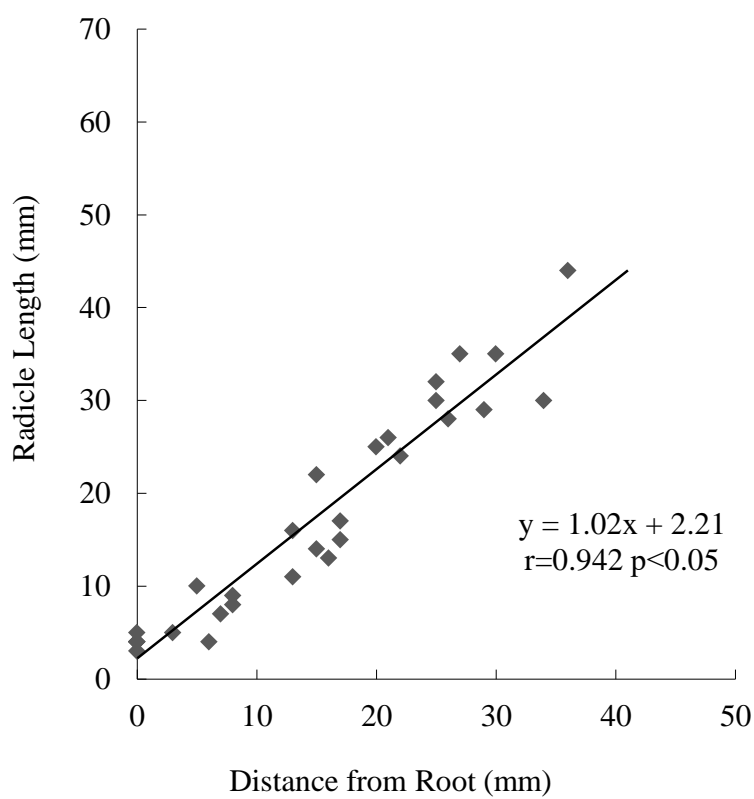

- Radicle L Linear (Radicle)

Fig. 1: Radicle elongation of lettuce grown in agar with no mucuna plant as untreated control (left) and with Mucuna pruriens var. utilis cv. fvb. (Right)

Table 3: Germination Percentages of Lettuce Seed 3 Days after Incubation with Oven-Dried Mucuna Leaves Using the Sandwich Method. Mucuna genotypes Percentage Germination (\%)

\begin{tabular}{lcc} 
& $10 \mathrm{mg}$ oven-dried leaves & 50 mg oven-dried leaves \\
\hline Mucuna pruriens var. utilis cv. fvb (U.S.A) & $100^{\mathrm{NS}}$ & $98.3^{\mathrm{NS}}$ \\
Mucuna pruriens var. utilis cv. hassjo (Japan) & $100^{\mathrm{NS}}$ & $100^{\mathrm{NS}}$ \\
Mucuna pruriens var. utilis cv preta (Brazil) & $100^{\mathrm{NS}}$ & $100^{\mathrm{NS}}$ \\
Mucuna pruriens var. utilis cv. cinza (Brazil) & $100^{\mathrm{NS}}$ & $98.3^{\mathrm{NS}}$ \\
Mucuna pruriens GA/94/002 (Ghana) & $100^{\mathrm{NS}}$ & $96.6^{\mathrm{NS}}$ \\
Mucuna pruriens $82 / 507$ (Ghana) & $100^{\mathrm{NS}}$ & $98.3^{\mathrm{NS}}$ \\
Mucuna pruriens $82 / 116$ (Ghana) & $100^{\mathrm{NS}}$ & $100^{\mathrm{NS}}$ \\
Mucuna pruriens $82 / 508$ (Ghana) & $100^{\mathrm{NS}}$ & $100^{\mathrm{NS}}$ \\
\hline
\end{tabular}

Table 4: Effects of Root Exudates from Mucuna Genotypes on Germination Percentages of Lettuce Seeds

\section{Mucuna genotypes}

Mucuna pruriens var. utilis cv. fvb (U.S.A)

Mucuna pruriens var. utilis cv. hassjo (Japan)

Mucuna pruriens var. utilis cv preta (Brazil)

Mucuna pruriens var. utilis cv. cinza (Brazil)

Mucuna pruriens GA/94/002 (Ghana)

Mucuna pruriens 82/507 (Ghana)

Mucuna pruriens 82/116 (Ghana)

Mucuna pruriens 82/508 (Ghana)

The germination percentages were calculated using the mean of three replicate samples. ${ }^{\text {NS }}$ indicates no significant $(\mathrm{p} \leq 0.05)$ difference among the germination percentages that were observed

Hachinohe and Matsumoto, [28] proposed that the phytotoxicity of L-DOPA might be due to the reactive oxygen species generated by the melanin synthesis pathway. Growth inhibition of cucumber root was observed when treated with L-DOPA. The inhibition occurred due to the quinopratein formation and mitochondrial impairment Mushtaq et al.,

\section{Germination percentage $(\%)$}

$98.0^{\mathrm{NS}}$
$97.0^{\mathrm{NS}}$
$97.0^{\mathrm{NS}}$
$97.0^{\mathrm{NS}}$
$97.8^{\mathrm{NS}}$
$97.0^{\mathrm{NS}}$
$97.5^{\mathrm{NS}}$
$96.0^{\mathrm{NS}}$

$98.0^{\mathrm{NS}}$

$97.0^{\mathrm{NS}}$

$97.0^{\mathrm{NS}}$

$97.8^{\mathrm{NS}}$

$97.5^{\mathrm{NS}}$

$96.0^{\mathrm{NS}}$

[27]. 


\section{Conclusion}

In conclusion, for a receptor plant like lettuce, the radicle elongation was inhibited more than the hypocotyl elongation by both leaf leachates and root exudates in the study. The inhibitory effect of the root exudates on the radicle elongation was higher on lettuce seedlings that were closer to the roots of mucuna. This result suggests that under field conditions, root exudates from mucuna may only have effect on plants that are very close to the roots. For the mucuna leaf leachates, the inhibitory effect depended on the application rate of the oven-dried leaves. Though the germination percentage of lettuce was not affected by both mucuna root exudates and leaf leachates, there were some discolorations of the radicle tip especially in the plant-box method. This results suggest that, the planting distance and the biomass production of mucuna when used as ground cover crop is necessary to optimize its effectiveness in weed control.

\section{Acknowledgement}

We are thankful to the Plant Genetic Resources Research Institute (Bunso, Ghana) and the Laboratory of International Agro-Biological Resources and Allelopathy at Tokyo University of Agriculture and Technology for the mucuna seeds. This research was supported by the grant-in-aid for research work on Agriculture and Food Science (25029AB) from the Ministry of Agriculture, Forestry and Fisheries of Japan. This work was also supported by JSPS KAKENHI Grant Number 26304024.

\section{Conflict of interest}

The authors declare that there is no conflict of interest associated with this publication.

\section{References}

[1] Akobundu, I. O. (1987). Weed Science in the Tropics; Principles and Practices. Ibadan, Nigeria: John Wiley and Sons Ltd. (pp. 1, 2, 25, 54).

[2] Heap, I. (2014). The International Survey of Herbicide Resistant Weeds. Online. Internet. Available www.weedscience.org Accessed on Wednesday, April 22, 2015.

[3] Osei-Bonsu, P., Buckles, D., Soza, F. R. and Asibuo, J. Y. (1996). Edible cover crops. ILEIA, Newsletter 30-31.

[4] Lawson I. Y. D., Dzomeku I. K., Asempa R., and Benson S. (2006). Weed Control in Maize Mucuna and Canavalia as Intercrops in the Northern Guinea Savanna Zone of Ghana. Journal of Agronomy. 5, 621-625. http://dx.doi.org/10.3923/ja.2006.621.625.

[5] Udensi, E.U., Akobundu, I.O., Ayeni, A.O., and Chikoye, D. (1999). Management of cogon grass (lmperata cylindrica) using mucuna (Mucuna pruriens var. utilis) and herbicides. Weed Technology. 13, 201-208.

[6] Chikoye, D. and Ekeleme, F. (2001). Characteristics of ten mucuna accessions and their effects on the dry matter of Imperata cylindrica (L.) Rauesch. Biological Agriculture and Horticulture. 18, 191-201. http://dx.doi.org/10.1080/01448765.2001.9754883.

[7] Osei, K., Moss, R., Nafeo, A., Addico, R., Agyemang A., and Asante J. S. (2011). Managing nematode pests and improving yield of pineapple with Mucuna pruriens in Ghana. Journal of Entomology and Nematology. 3(1), 20-24.

[8] Nyalemegbe, K. K., Agbozo, G. K., and Addo-Quaye, A. A. (2011). The effect of mucuna residue management on the growth and yield of maize. Agricultural Science Research Journal. 1(10), 259-263.

[9] Nicol, J. M., Turner, S. J., Coyne D. L., den Nijs L., Hockland, S., and Maafi, Z. (2011). Current nematode threats to world Agriculture, in: Jones et al. (Eds.), Genomics and Molecular Genetics of Plant-Nematode Interactions) 21-43. http://dx.doi.org/10.1007/978-94-007-0434-3 2.

[10] Zasada, I. A., Klassen W., Meyer S. L. F., Codallo, M., and Abdul-Baki, A. A. (2006). Mucuna (Mucuna pruriens) extracts: Impact on Meloidogyne incognita survival and on Lycopersicon esculentum and Lactuca sativa germination and growth. Pest Management Science. 62, 1122-1127. http://dx.doi.org/10.1002/ps.1281.

[11] Arim, O. J., Waceke J. W., Waudo S. W., and Kimenju, J. W. (2006). Effects of Canavalia ensiformis and Mucuna pruriens intercrops on Pratylenchus zeae damage and yield of maize in subsistence agriculture. Plant soil. 284, 243-251. http://dx.doi.org/10.1007/s11104-006-0053$\underline{9}$.

[12] Rodriguez-Kabana, R., Pinochet, J., Robertson, D. G., and Wells, L. (1992). Crop Rotation Studies with Mucuna (Mucuna deeringiana) for the Management of Meloidogyne spp. Journal of Nematology. 24(4S), 662-668.

[13] Weaver, D. B., Rodriguez-Kabana, R., and Carden, E. L. (1998). Mucuna and Bahiagrass as rotation crops for management of Meloidegyne spp. and Heterodera glycines in soybean. Journal of Nematology. 30(4), 563-568.

[14] Fujii, Y., Hiradate, S. (2007). Allelopathy: New Concepts and Methodology. Enfield, USA. Science Publishers.

[15] Callaway, R. M., and Ridenour, W. M. (2004). Novel Weapons: Invasive Success and the Evolution of Increased Competitive Ability. Frontiers in Ecology Environment. 2(8), 436-443. http://dx.doi.org/10.1890/1540-9295(2004)002[0436:NWISAT]2.0.CO;2.

[16] Duke, S. O. (2010). Allelopathy: Current status of research and future of the discipline: A commentary. Allelopathy Journal. 2(1), 17-30.

[17] Vyvyan, J. R. (2002). Allelochemicals as leads for new herbicides and agrochemicals. Tetrahedron. 58, 1631-1646. http://dx.doi.org/10.1016/S0040-4020(02)00052-2.

[18] Fujii, Y. (2003). Allelopathy in the natural and agricultural ecosystems and isolation of potent allelochemicals from mucuna (Mucuna pruriens) and hairy vetch (Vicia villosa). Biological Sciences in Space. 17(1), 6-13. http://dx.doi.org/10.2187/bss.17.6.

[19] Fujii, Y., Shibuya T., and Yasuda T. (1991). L-3, 4-Dihydroxyphenylalanine as an allelochemical candidate from Mucuna pruriens (L) DC. Var. utilis. Agricultural and Biological Chemistry. 55(2), 617-618. http://dx.doi.org/10.1271/bbb1961.55.617.

[20] Fujii, Y., Shibuya T., and Yasuda T. (1992). Allelopathy of mucuna: Its discrimination and identification of L-DOPA as a candidate of allelopathic substance. Japan Agricultural Research Quarterly. 25, 238-247.

[21] Fujii, Y. (1994). Screening of Allelopathic candidates by new specific discrimination and assessment methods for allelopathy, and the inhibition of L-DOPA as the allelopathic substance from the most promising mucuna (Mucuna pruriens). Bulletin of National Institute of Agro-Environmental Sciences. 10, 115-218 (in Japanese with English summary).

[22] Fujii, Y., Shibuya, T., Nakata, K., Itani, T., Hiradate, S. and Parvez, M. M. (2004). Assessment Method for the Allelopathic Effect from Leaf Leachate. Weed Biology Management. 4, 19-23. http://dx.doi.org/10.1111/j.1445-6664.2003.00113.x. 
[23] Shiraishi, S., Watanabe, I., Kuno, K., and Fujii, Y. (2002). Allelopathic activity of leaching from dry leaves and exudate from roots of ground cover plants assayed on agar. Weed Biology Management. 2, 133-142. http://dx.doi.org/10.1046/j.1445-6664.2002.00063.x.

[24] Nishihara, E., Parvez, M. M., Araya, H., Kawashima, S., and Fujii, Y. (2005). L-3-(3, 4-Dihydroxyphenyl)alanine (L-DOPA), an allelochemical exuded from mucuna (Mucuna pruriens) roots. Plant Growth Regulation. 45, 113-120. http://dx.doi.org/10.1007/s10725-0050610-x.

[25] Bhadoria, P. B. S. (2011). Allelopathy: A Natural Way towards Weed Management. American Journal of Experimental Agriculture. 1(1), 7-20.

[26] Eucharia, O. N., and Edward O. A. (2010). Allelopathy as expressed by Mucuna pruriens and the possibility for weed management. International Journal of Plant Physiology and Biochemistry 2(1), 1-5.

[27] Mushtaq, M. N., Sunohara, Y., and Matsumoto, H. (2013). Allelochemical L-DOPA induces quinoprotein adducts and inhibits NADH dehydrogenase activity and root growth of cucumber. Plant Physiology and Biochemistry. 70, 374-378. http://dx.doi.org/10.1016/i.plaphy.2013.06.003.

[28] Hachinohe, M., and Matsumoto, H. (2007). Involvement of melanin synthesis and reactive oxygen species in phytotoxic action of L-DOPA in carrot cells. Crop Protection. 26, 294-298. http://dx.doi.org/10.1016/j.cropro.2005.06.011. 